\title{
New-onset postoperative atrial fibrillation is associated with worse long-term outcome in critically ill patients after non-cardiac surgery: 3-year follow-up of a case-control study
}

\section{Min Xie}

Peking University First Hospital https://orcid.org/0000-0002-9006-4176

Shuang-Ling Li

Peking University First Hospital

Jia-Xin Pan

Peking University First Hospital

Sai-Nan Zhu

Peking University First Hospital

Dong-Xin Wang ( $\square$ wangdongxin@hotmail.com )

https://orcid.org/0000-0002-3205-1836

\section{Research article}

Keywords: Non-cardiac surgery; new-onset postoperative atrial fibrillation; long-term outcomes; major adverse cardiovascular events

Posted Date: April 19th, 2019

DOI: https://doi.org/10.21203/rs.2.9255/v1

License: (c) (i) This work is licensed under a Creative Commons Attribution 4.0 International License.

Read Full License 


\section{Abstract}

Background The impact of new-onset postoperative atrial fibrillation (POAF) on long-term outcomes of patients after non-cardiac surgery remains controversial. Here we report the 3-year follow-up of a previous case-control study to determine the relationship between new-onset POAF and long-term outcomes in patients after non-cardiac surgery. Methods In a previous case-control study, 213 patients who were admitted to the intensive care unit (ICU) after non-cardiac surgery were included; of them 71 were in the POAF group and 142 the control group. A telephone interview was performed with patients or their family members at 3 years after surgery. The primary endpoint was the incidence of major adverse cardiovascular events (MACEs) within 3 years, including cardiovascular death, non-fatal cardiac arrest, acute myocardial infarction, congestive heart failure, and ischemic stroke. A logistic regression model was established to assess the association between the occurrence of new-onset POAF and the development of 3-year MACEs. Results 202 patients completed the 3-year follow-up and were included in the analysis; of them 68 were in the POAF group and 134 were in the control group. The incidence of 3year MACEs was higher in the POAF group than in the control group $(64.7 \%$ [44/68] vs. $23.1 \%$ [31/134], $\mathrm{p}<0.001)$. After correction for confounding factors, new-onset POAF was independently associated with an increased risk of 3-year MACEs (odds ratio 5.448, 95\% confidence interval 2.202-13.481, p<0.001). Conclusions For adult patients admitted to the ICU after non-cardiac surgery, new-onset POAF was an independent risk factor for the development of MACEs within 3 years.

\section{Introduction}

New-onset postoperative atrial fibrillation (POAF) is the most commonly occurred arrhythmia in patients after surgery [1]. The reported incidence varies widely, from $0.39 \%$ to $29 \%$, according to the patient populations and the types of surgeries [1-14]. In our previous study, $2.7 \%$ of patients admitted to the intensive care unit (ICU) after non-cardiac surgery developed new-onset POAF. Of them, $77.5 \%$ occurred within the first 3 days after surgery, $87.3 \%$ had rapid ventricular rate ( $>110$ beats per minute), $39.4 \%$ had a significant drop in blood pressure (>30\% from baseline), and 33.8\% complained discomfort (including palpitation, chest distress, and precordial pain or discomfort). Sepsis, hypokalemia, congestive heart failure and other new-onset arrhythmias were risk factors of new-onset POAF [15].

The occurrence of POAF is associated with worse outcomes. In patients after cardiac surgery, new-onset POAF is associated with increased hospital readmission, late atrial fibrillation (AF) and thromboembolic disease, as well as long-term mortality [16-21]. In patients after major non-cardiac surgery, new-onset POAF is reported to be associated with higher in-hospital mortality, longer hospital stays, higher health care costs [9], and increased long-term cardiovascular events (including acute myocardial infarction and stroke) $[10,12,13]$. In a recent prospective cohort study of ICU patients (including surgical patients), newonset AF is associated with increased 1-year mortality [22]. On the other hand, negative results were also reported regarding the relationship between new-onset POAF and long-term survival $[11,18,23]$. 
The purpose of this 3-year follow-up study was to investigate the association between new-onset POAF and long-term outcomes in critically ill patients after non-cardiac surgery.

\section{Methods}

\section{Study design}

This was a 3-year follow-up of patients enrolled in a previous case-control study [15]. The study protocol was approved by the Clinical Research Ethics Committee of Peking University First Hospital (2016[1110]). Since the study was pure observational, the Ethics Committee agreed to waive the written informed consent for this subsequent telephone contact. But all participants or their family members were informed of the purpose and contents of the current study, and provide oral consents via telephone before data collection.

\section{Patient recruitment}

In the previous study, 71 adult patients who were admitted to the ICU after non-cardiac surgery from January 1, 2011 to December 31, 2013 and developed new-onset POAF during ICU stay were enrolled. One hundred and forty-two control patients (without new-onset POAF) were enrolled in a ratio of 1:2. The matching conditions included the following: same gender, same type of surgery, age gap within 4 years, and the closest date of surgery. The exclusion criteria were the same for both cases and control subjects, i.e., a previous history of atrial fibrillation, atrial fibrillation revealed by preoperative examination, or missing data.

\section{Collection of baseline and perioperative data}

Baseline data included demographic variables (age, sex, body mass index), surgical diagnosis, preoperative comorbidities (chronic heart failure, hypertension, coronary heart disease, diabetes mellitus, chronic obstructive pulmonary disease, asthma, chronic renal failure and non-AF arrhythmia), main results of preoperative examination (including echocardiogram), and American Society of Anesthesiologist (ASA) classification. Perioperative data included type and duration of surgery, complexity [24] and cardiac risk [25] of surgery, type of anesthesia, intraoperative fluid balance, main laboratory test results after surgery (hemoglobin [HGB], cardiac troponin I [CTnl], brain natriuretic peptide [BNP], serum potassium, and serum magnesium), Acute Physiology and Chronic Health Evaluation (APACHE) II score at ICU admission, the worst physiological parameters during ICU stay, occurrence of postoperative complications, and pathological diagnoses (including the tumor, node and metastasis [TNM] stage for cancer [26]).

Postoperative major adverse cardiovascular events (MACEs) indicated those that occurred during hospital stay after surgery (up to 30 days) and included cardiovascular death, nonfatal cardiac arrest, acute myocardial infarction, congestive heart failure, and ischemic stroke. Cardiovascular death referred to any death caused by specific cardiovascular diseases (including myocardial infarction [I21.X in the 
International Classification of Diseases-10th Revision code], heart failure [I50.X], arrhythmia [I49.900], and cardiogenic shock [R57.001]), which might be combined with other diseases. Non-fatal cardiac arrest (146.9) referred to cardiac arrest (ventricular fibrillation, pulseless ventricular tachycardia, asystole, and pulseless electrical activity) caused by various reasons, followed by return of spontaneous circulation after cardiopulmonary resuscitation (CPR), and patient survived. Acute myocardial infarction (I21.X) was diagnosed when the $\mathrm{CTnl}$ concentration was higher than the diagnostic criteria for myocardial infarction, together with the emergence of new Q wave $(\geq 0.03 \mathrm{~s})$ or the persistent change of ST-T segment $(\geq 4$ days). Congestive heart failure (I50.X) referred to the acute attack or aggravation of the symptoms or signs of heart failure, accompanied by BNP elevation $(>400 \mathrm{pg} / \mathrm{ml})$, and required medical treatment. Ischemic stroke referred to a new-onset, persistent (>24 hours) focal neurologic deficit with computed tomography or magnetic resonance imaging evidence of cerebral infarction (163.9).

Other postoperative complications were generally defined as new-onset complications other than MACEs during hospital stay (up to 30 days) after surgery, which were harmful for postoperative recovery and required therapeutic intervention.

\section{3-year follow-up}

The 3-year follow-up was carried out by telephone interview with patients and/or their family members. Prior to the follow-up, the investigator reviewed the patients' medical records within 3 years. During the follow-up interview, the condition of patients after discharge and the occurrence of MACEs were inquired and collected in detail. Long-term MACEs included cardiovascular death, nonfatal cardiac arrest, acute myocardial infarction, congestive heart failure, and ischemic stroke. For all patients, the diagnoses of MACEs were confirmed by another senior ICU physician who was not aware of patients' study group assignment. For patients who died within 3 years, the date of death was recorded.

\section{Study endpoints}

The primary endpoint was the incidence of MACEs within 3 years after surgery. Secondary endpoints included the incidences of MACEs and other complications during hospital stay (up to 30 days), lengths of stay in ICU and hospital, all-cause in-hospital mortality (up to 30 days), and 3-year overall survival after surgery.

\section{Statistical Analysis}

Continuous variables were compared with the independent samples $t$ test or Mann-Whitney $U$ test. Categorical variables were compared with the $\chi^{2}$ test or Fisher exact test. Time-to-event variables were calculated with the Kaplan-Meier estimator, with differences between groups assessed by the log-rank test. To assess the risk adjusted association between the new-onset POAF and the occurrence of MACEs within 3 years, univariate logistic regression analyses were performed first; independent variables with $p<0.10$ were included in a multivariate logistic regression model with a backward (Wald) stepwise 
procedure. A two-tailed $p$ value $<0.05$ was considered as statistically significant. All statistical analyses were performed with SPSS 25.0 software package (SPSS Inc, Chicago, III, USA).

\section{Results}

\section{Patients}

Of the 213 patients enrolled in our previous study (71 in the POAF group and 142 in the control group), 11 $(5.2 \%)$ were lost to follow-up at 3 years after surgery. The remaining 202 patients completed the 3-year follow-up and were included in the final analysis; of these, 68 were in the POAF group and 134 in the control group. Postoperative 3-year follow-up was performed between January 1, 2014 and December 31, 2016 (Figure 1).

\section{Baseline characteristics and perioperative data}

Baseline characteristics were comparable between the two groups (Table 1). Compared with patients in the control group, those in the POAF group had higher proportion of emergency surgery $(p=0.005)$ and higher APACHE II score at ICU admission ( $p=0.003)$; they had lower levels of hemoglobin $(p=0.003)$, serum potassium $(p<0.001)$ and serum magnesium $(p=0.005)$, but higher levels of troponin I $(p<0.001)$ and brain natriuretic peptide $(p<0.001)$ during ICU stay (Table 2$)$. There were no significant differences regarding the proportion of pathologically diagnosed cancer and the distribution of cancer stages between the two groups (Table 3).

\section{Results of 3-year follow-up}

The incidence of 3-year MACEs was higher in the POAF group than in the control group $(64.7 \%$ [44/68] vs. $23.1 \%$ [31/134], odds ratio [OR] 6.091, 95\% confidence interval [CI] 3.215-11.543, $p<0.001)$. Among individual incidences of MACEs, those of congestive heart failure $(p<0.001)$ and ischemic stroke $(p=0.032)$ were higher in the POAF group than in the control group.

The incidences of in-hospital MACEs and other complications after surgery were higher in the POAF group than in the control group (both $p<0.001$ ). The duration of mechanical ventilation in patients who were admitted to the ICU with endotracheal intubation was longer $(p<0.001)$, the lengths of stay in ICU and hospital after surgery in all patients were also longer (both $p<0.001$ ) in the POAF group than in the control group. All-cause in-hospital mortality was higher $(p=0.006)$, whereas 3-year overall survival was shorter $(p=0.043)$ in the POAF group than in the control group (Table 4; Figure 2).

\section{Association between new-onset POAF and 3-year MACEs}

Apart from new-onset POAF, univariable analyses identified 9 other factors that were associated with 3year MACEs $(p<0.10)$, including preoperative coronary heart disease, non-AF arrhythmia and left atrial enlargement, emergency surgery, APACHE II score at ICU admission, as well as hemoglobin $<110 \mathrm{~g} / \mathrm{L}$, troponin I $>0.04 \mathrm{ng} / \mathrm{ml}$, brain natriuretic peptide $>100 \mathrm{pg} / \mathrm{ml}$ and occurrence of other complications after 
surgery (Supplement 1). After correction for confounding factors, new-onset POAF was associated with an increased risk of 3-year MACEs (OR 5.448, 95\% Cl 2.202-13.481, $p<0.001$ ). Among other factors, preoperative coronary heart disease (OR 2.974, 95\% Cl 1.126-7.858, $p=0.028)$ and postoperative troponin I $>0.04 \mathrm{ng} / \mathrm{ml}(\mathrm{OR} 19.137,95 \% \mathrm{Cl} 5.642-64.909, p<0.001)$ were also associated with increased risks of $3-$ year MACEs (Table 5).

\section{Discussion}

Results of the present study showed that, in patients admitted to the ICU after non-cardiac surgery, those who developed new-onset POAF had a higher incidence of MACEs and a shorter overall survival within 3 years after surgery. New-onset POAF was independently associated with an increased risk of 3-year MACEs.

A large database study from the United States revealed that, between 2004 and 2013, 1 of every 33 patients hospitalized for non-cardiac surgery developed perioperative major adverse cardiovascular and cerebrovascular events [27]. Different from cardiac surgery patients [16-19], available evidence regarding the impact of new-onset AF on the long-term outcomes after non-cardiac surgery are still controversial. For example, Gialdin and colleagues [10] found that perioperative AF was associated with an increased risk of long-term ischemic stroke; others also reported that patients with new-onset AF after cancer surgery were at increased risk of cardiovascular events within 1 year [12,13]. On the other hand, results of Meierhenrich and colleagues [23] showed that new-onset AF did not increase 2-year mortality in septic shock patients; long-term follow-ups of Cormack and colleagues [11] also showed that new-onset POAF did not affect oncologic outcomes. Differences in patient populations and surgical types may be responsible for different results.

In the present study, we followed up patients included in a previous retrospective case-control study at 3 years after surgery. In our previous results, $95.8 \%$ of new-onset POAF were transient, and only $4.2 \%$ became persistent [15]. But even so, new-onset POAF was significantly associated with an increased risk of 3-year MACEs. Our results provide further evidence that new-onset POAF may produce negative effects on long-term outcomes of patients admitted to the ICU after non-cardiac surgery. Considering that POAF is an easily diagnosed and preventable arrhythmia, whether the prevention of POAF can improve the longterm outcomes in this patient population deserves further study.

The exact mechanisms leading to increased long-term MACEs by new-onset POAF remain not totally clear but may include the following. Firstly, the effect of inflammation and stress response [28-31]. Newonset $A F$ is often seen in patients with more intense inflammation and stress response [6,23,29,32,33], including sepsis [15] and septic shock [34]. POAF is usually triggered by surgery-related inflammation and stress response in elderly patients with comorbid cardiac disease [30]. Although POAF is transient in most cases, the intense and persistent inflammation and stress response might have worsened the long-term outcomes. Secondly, the effect of recurrent or chronic AF. It was found that recurrent or chronic AF is more likely to occur in patients with new-onset POAF $[17,20,21,35]$. And even a short period ( $>6$ minutes) 
of subclinical fibrillation is associated with an increased risk of stroke and embolism [36], and subsequently affects late survival [16]. In our previous study, only a small part of patients with new-onset POAF (4.2\%) had persistent AF during hospital stay. However, it was possible that AF reoccurred or even became persistent in some patients after hospital discharge, and increased long-term MACEs after surgery.

In the present study, the 3-year overall survival was shorter in patients with new-onset POAF. The occurrence of MACEs might have led to a shortened survival time [35]. In addition, other factors might also have exerted impact, such as cancer. In the present study, $78.2 \%$ of all patients underwent surgery for cancer. Although the staging of cancers did not differ significantly between the two groups, the proportions with advanced-stage cancer were slightly higher in patients in the POAF group. The confounding effect of cancer stage on long-term survival cannot be excluded. The impact of new-onset POAF on long-term survival requires further study.

There are several limitations of the present study. Firstly, because of the low incidence of POAF, our previous study was a case-control study with a small sample size and single-center data. This limited the generalizability of the present results. Secondly, the long-term outcome data was collected through telephone interview. Although detailed diagnostic criteria were set to define the endpoints, there might be some bias. Lastly, as results of 3-year follow-up of a case-control study, the effects from unidentified confounding factors could not be excluded. Nevertheless, the results from the present study provide important clues for further interventional trials.

\section{Conclusions}

Our study found that, for adult patients admitted to the ICU after non-cardiac surgery, those with new-set POAF had higher incidence of 3-year MACEs and shorter overall survival. New-onset POAF was independently associated with an increased risk of 3-year MACEs. Interventional studies are required to elucidate whether prevention of new-onset POAF can improve long-term outcomes.

\section{References}

1. Walsh SR, Oates JE, Anderson JA, Blair SD, Makin CA, Walsh CJ. Postoperative arrhythmias in colorectal surgical patients: incidence and clinical correlates. Colorectal Dis. 2006 Mar;8(3):212-6.

2. Christians KK, Wu B, Quebbeman EJ, Brasel KJ.. Postoperative atrial fibrillation in noncardiothoracic surgical patients. Am J Surg. 2001;182(6):713-5.

3. Vaporciyan AA, Correa AM, Rice DC, Roth JA, Smythe WR, Swisher SG, et al. Risk factors associated with atrial fibrillation after noncardiac thoracic surgery: analysis of 2588 patients. J Thorac Cardiovasc Surg. 2004;127(3):779-86.

4. Amar D, Zhang H, Heerdt PM, Park B, Fleisher M, Thaler HT. Statin use is associated with a reduction in atrial fibrillation after noncardiac thoracic surgery independent of c-reactive protein. Chest. 2005;128(5):3421-7. 
5. Passman RS, Gingold DS, Amar D, Lloyd-Jones D, Bennett CL, Zhang H, et al. Prediction rule for atrial fibrillation after major noncardiac thoracic surgery. Ann Thorac Surg. 2005;79(5):1698-703.

6. Siu CW, Tung HM, Chu KW, Jim MH, Lau CP, Tse HF. Prevalence and predictors of new-onset atrial fibrillation after elective surgery for colorectal cancer. Pacing Clin Electrophysiol. 2005;28 Suppl 1:S120-3.

7. Sohn GH, Shin DH, Byun KM, Han HJ, Cho SJ, Song YB, et al. The incidence and predictors of postoperative atrial fibrillation after noncardiothoracic surgery. Korean Circ J. 2009;39(3):100-4.

8. Onaitis M, D'Amico T, Zhao Y, O'Brien S, Harpole D.. Risk Factors for Atrial Fibrillation After Lung Cancer Surgery: Analysis of The Society of Thoracic Surgeons General Thoracic Surgery Database. Ann Thorac Surg. 2010;90(2):368-74.

9. Bhave, PD, Goldman, LE, Vittinghoff, E, Maselli, J, Auerbach, A. Incidence, Predictors, and Outcomes associated with Post-operative Atrial Fibrillation after Major Non-Cardiac Surgery. Am Heart J, 2012, 164(6):918-24.

10. Gialdini G, Nearing K, Bhave PD, Bonuccelli U, ladecola C, Healey JS, et al. Perioperative atrial fibrillation and the long-term risk of ischemic stroke. JAMA. 2014;312(6):616-22.

11. Mc Cormack O, Zaborowski A, King S, Healy L, Daly C, O'Farrell N, et al. New-onset atrial fibrillation post-surgery for esophageal and junctional cancer incidence, management, and impact on short- and long-term outcomes. Ann Surg. 2014 Nov;260(5):772-8.

12. Nassoiy SP, Blackwell RH, Kothari AN, Besser S, Gupta GN, Kuo PC, et al. New onset postoperative atrial fibrillation predicts long-term cardiovascular events after gastrectomy. Am J Surg. 2016 Mar;211(3):559-64.

13. Blackwell RH, Ellimoottil C, Bajic P, Kothari A, Zapf M, Kliethermes S et al. Postoperative Atrial Fibrillation Predicts Long-Term Cardiovascular Events after Radical Cystectomy. J Urol. 2015, 194(4):944-9.

14. Rozencwajg S, Desthieux C, Szymkiewicz O, Ynineb Y, Fulgencio JP, Bonnet F. The risk of atrial fibrillation after pneumonectomy is not impaired by preoperative administration of dexamethasone. A cohort study. Anaesth Crit Care Pain Med. 2017;36(3):185-9.

15. Xie M, Wang DX, Li SL. Risk factors for atrial fibrillation after non-cardiac surgery in intensive care units. Chinese Journal of Multiple Organ Diseases in the Elderly. 2018;17 (6), 401-6.

16. Mariscalco G, Klersy C, Zanobini M, Banach M, Ferrarese S, Borsani P, et al. Atrial Fibrillation After Isolated Coronary Surgery Affects Late Survival. Circulation. 2008;118(16):1612-8.

17. Bramer S, van Straten AH, Soliman Hamad MA, van den Broek KC, Maessen JG, Berreklouw E. NewOnset Postoperative Atrial Fibrillation Predicts Late Mortality After Mitral Valve Surgery. Ann Thorac Surg. 2011;92(6):2091-6.

18. Mariscalco G, Karl Gunnar Engström. Postoperative Atrial Fibrillation Is Associated With Late Mortality After Coronary Surgery, but Not After Valvular Surgery. Ann Thorac Surg. 2009, 88(6):18716. 
19. LaPar DJ, Speir AM, Crosby IK, Fonner E Jr, Brown M, Rich JB, et al. Postoperative Atrial Fibrillation Significantly Increases Mortality, Hospital Readmission, and Hospital Costs. Ann Thorac Surg. 2014;98(2):527-33.

20. Filardo G, Hamilton C, Hamman B, Hebeler RF Jr, Adams J, Grayburn P.. New-Onset Postoperative Atrial Fibrillation and Long-Term Survival After Aortic Valve Replacement Surgery. Ann Thorac Surg. 2010, 90(2):474-9.

21. Lee SH, Kang DR, Uhm JS, Shim J, Sung JH, Kim JY, et al. New-onset atrial fibrillation predicts longterm newly developed atrial fibrillation after coronary artery bypass graft. Am Heart J. 2014 Apr;167(4):593-600.e1.

22. Arrigo M, Ishihara S, Feliot E, Rudiger A, Deye N, Cariou A, et al. New-onset atrial fibrillation in critically ill patients and its association with mortality: A report from the FROG-ICU study. Int $J$ Cardiol. 2018;266:95-9.

23. Meierhenrich R, Steinhilber E, Eggermann C, Weiss M, Voglic S, Bögelein D, et al. Incidence and prognostic impact of new-onset atrial fibrillation in patients with septic shock: a prospective observational study. Crit Care. 2010;14(3):R108.

24. O'Neill F, Carter E, Pink N, Smith I. Routine preoperative tests for elective surgery: summary of updated NICE guidance. BMJ. 14;354:i3292.

25. Eagle KA, Berger PB, Calkins H, Chaitman BR, Ewy GA, Fleischmann KE, et al. ACC/AHA Guideline Update for Perioperative Cardiovascular Evaluation for Noncardiac Surgery--Executive Summary. A report of the American College of Cardiology/American Heart Association Task Force on Practice Guidelines (Committee to Update the 1996 Guidel. Circulation. 2002, 39(3):542-53.

26. Edge SB, Compton CC. The American Joint Committee on Cancer: the 7th edition of the AJCC cancer staging manual and the future of TNM. Ann Surg Oncol. 2010;17(6):1471-4.

27. Nathaniel RS, Navdeep G, Harish R, Yu Guo, Jeffrey SB, et al. Trends in Perioperative Major Adverse Cardiovascular and Cerebrovascular Events associated with Non-Cardiac Surgery, JAMA Cardiol. 2017; 2(2): 181-7.

28. Christopher JB, Richard AA, and Gregory YHL. Is atrial fibrillation an inflammatory disorder? Eur Heart J. 2005, 27(2):136-49.

29. Issac TT, Dokainish H, Lakkis NM. Role of Inflammation in Initiation and Perpetuation of Atrial Fibrillation: A Systematic Review of the Published Data. J Am Coll Cardiol. 2007;50(21):2021-8.

30. Maesen B, Nijs J, Maessen J, Allessie M, Schotten U. Post-operative atrial fibrillation: a maze of mechanisms. Europace. 2012;14(2):159-74.

31. Kuipers S, Klein Klouwenberg PM, Cremer OL.. Incidence, risk factors and outcomes of new-onset atrial fibrillation in patients with sepsis: a systematic review. Crit Care. 2014;18(6):688.

32. Wu ZK, Laurikka J, Vikman S, Nieminen R, Moilanen E, Tarkka MR. High Postoperative Interleukin-8 Levels Related to Atrial Fibrillation in Patients Undergoing Coronary Artery Bypass Surgery. World J Surg. 2008;32(12):2643-9. 
33. Amar D, Goenka A, Zhang H, Park B, Thaler HT. Leukocytosis and increased risk of atrial fibrillation after general thoracic surgery. Ann Thorac Surg. 2006;82(3):1057-61.

34. Kanji S, Williamson DR, Yaghchi BM, Albert M, McIntyre L; Canadian Critical Care Trials Group.. Epidemiology and management of atrial fibrillation in medical and noncardiac surgical adult intensive care unit patients. J Crit Care. 2012;27(3):326.e1-8.

35. Ahlsson A, Fengsrud E, Bodin L, Englund A. Postoperative atrial fibrillation in patients undergoing aortocoronary bypass surgery carries an eightfold risk of future atrial fibrillation and a doubled cardiovascular mortality. Eur J Cardiothorac Surg. 2010 Jun;37(6):1353-9.

36. Brambatti M, Connolly SJ, Gold MR, Morillo CA, Capucci A, Muto C, et al. Temporal Relationship Between Subclinical Atrial Fibrillation and Embolic Events. Circulation, 2014;129(21):2094-9.

\section{Tables}

Table 1. Baseline data 


\begin{tabular}{|c|c|c|c|}
\hline & POAF group $(\mathrm{n}=68)$ & Control group $(\mathrm{n}=134)$ & $p$ value \\
\hline Age (years) & $72.3 \pm 10.8$ & $72.7 \pm 10.2$ & 0.768 \\
\hline Male & $36(52.9 \%)$ & $72(53.7 \%)$ & 0.915 \\
\hline Body mass index $\left(\mathrm{kg} / \mathrm{m}^{2} \square\right.$ & $23.2 \pm 4.3$ & $22.8 \pm 3.2$ & 0.498 \\
\hline \multicolumn{4}{|l|}{ Preoperative complicated diseases } \\
\hline Chronic heart failure $^{a}$ & $1(1.5 \%)$ & $6(4.5 \%)$ & 0.486 \\
\hline Hypertension & $39(57.4 \%)$ & $82(61.2 \%)$ & 0.599 \\
\hline Coronary heart disease & $18(26.5 \%)$ & $33(24.6 \%)$ & 0.776 \\
\hline Diabetes mellitus & $9(13.2 \%)$ & $25(18.7 \%)$ & 0.330 \\
\hline Chronic obstructive pulmonary disease & $3(4.4 \%)$ & $3(2.2 \%)$ & 0.674 \\
\hline Asthma & $3(4.4 \%)$ & $5(3.7 \%)$ & $>0.999$ \\
\hline Chronic kidney disease ${ }^{\mathrm{b}}$ & $4(5.9 \%)$ & $9(6.7 \%)$ & $>0.999$ \\
\hline Non-AF arrhythmia ${ }^{\mathrm{c}}$ & $4(3.0 \%)$ & $7(10.3 \%)$ & 0.066 \\
\hline \multicolumn{4}{|l|}{ Preoperative echocardiographic abnormality } \\
\hline Left atrial enlargement & $19(35.8 \%)$ & $22(24.7)$ & 0.157 \\
\hline Pulmonary arterial systolic pressure $(\mathrm{mmHg})$ & $32.6 \pm 10.1$ & $30.8 \pm 11.0$ & 0.195 \\
\hline Left ventricular ejection fraction $<50 \%$ & $6(11.1 \%)$ & $10(10.6)$ & 0.929 \\
\hline Cardiac valves abnormality & $52(98.1 \%)$ & $86(96.6)$ & $>0.999$ \\
\hline Preoperative ASA classification & & & 0.498 \\
\hline I & $23(34.3 \%)$ & $37(27.4 \%)$ & \\
\hline II & $26(38.8 \%)$ & $67(49.6 \%)$ & \\
\hline III & $11(16.4 \%)$ & $21(15.6 \%)$ & \\
\hline IV & $7(10.2 \%)$ & $10(7.4 \%)$ & \\
\hline Duration from surgery to interview (month) & $36.6 \pm 1.3$ & $36.3 \pm 0.9$ & 0.086 \\
\hline
\end{tabular}

Data are presented as mean \pm SD or number $(\%)$.

POAF: postoperative atrial fibrillation; AF: atrial fibrillation; ASA: American Society of Anesthesiologist.

a Diagnosed according to the symptoms and signs of heart failure, including dyspnea, inability to lie flat at night, decreased activity tolerance, peripheral edema, signs of pulmonary congestion on chest X-ray, and/or elevated serum brain natriuretic peptide level. These symptoms and signs developed on the basis of underlying heart diseases. Diagnosis was confirmed by cardiologists and treatment was required before surgery. 
${ }^{\mathrm{b}}$ Glomerular filtration rate $<60 \mathrm{ml} / \mathrm{min} / 1.73 \mathrm{~m}^{2}$ lasting for more than 3 months. Diagnosis was confirmed by nephrologists.

${ }^{\mathrm{c}}$ Included sinus tachycardia (2 cases), sinus bradycardia (2 cases), atrial premature beat (2 cases), ventricular premature beat (1 case), supraventricular tachycardia (1 case), atrioventricular block (2 cases), and bundle branch block (1 case). Diagnosis was confirmed by preoperative electrocardiographic examination.

\section{Table 2. Perioperative data}




\begin{tabular}{|c|c|c|c|}
\hline & POAF group $(\mathrm{n}=68)$ & Control group ( $\mathrm{n}=134)$ & $P$ value \\
\hline Type of surgery & & & 0.995 \\
\hline Intra-abdominal & $41(60.3 \%)$ & $84(62.7 \%)$ & \\
\hline Intra-thoracic & $14(20.6 \%)$ & $27(20.1 \%)$ & \\
\hline Transurethral & $2(2.9 \%)$ & $3(2.2 \%)$ & \\
\hline Intra-cranial & $3(4.4 \%)$ & $6(4.4 \%)$ & \\
\hline Spinal and extremital & $8(11.8 \%)$ & $14(10.4 \%)$ & \\
\hline Duration of surgery (min) & $196(131,357)$ & $202(147,333)$ & 0.966 \\
\hline Complexity of surgery ${ }^{a}$ & & & 0.907 \\
\hline Intermediate & $3(4.2 \%)$ & $4(3.0 \%)$ & \\
\hline Major or complex & $65(95.6 \%)$ & $130(97.0 \%)$ & \\
\hline Cardiac risk of surgery ${ }^{b}$ & & & 0.930 \\
\hline Low & $3(4.4 \%)$ & $6(4.5 \%)$ & \\
\hline Intermediate & $64(94.1 \%)$ & 125 (93.3\%) & \\
\hline High & $1(1.5 \%)$ & $3(2.2 \%)$ & \\
\hline Type of anesthesia & & & 0.639 \\
\hline Neuraxial & $8(11.8 \%)$ & $22(16.4 \%)$ & \\
\hline General & $56(82.4 \%)$ & $106(79.1 \%)$ & \\
\hline Combined epidural-general & $4(5.9 \%)$ & $6(4.5 \%)$ & \\
\hline \multicolumn{4}{|l|}{ Intraoperative fluid balance } \\
\hline Fluid infusion (ml) & $2750(1862,4263)$ & $2300(1600,3925)$ & 0.162 \\
\hline Blood transfusion & $24(35.3 \%)$ & $43(32.1 \%)$ & 0.648 \\
\hline Emergency operation & $21(30.9 \%)$ & $19(14.2 \%)$ & 0.005 \\
\hline ICU admission with intubation & 45 (66.2\%) & $85(63.4 \%)$ & 0.700 \\
\hline APACHE II score at ICU admission ${ }^{c}$ & $12(9,17 \%)$ & $10(8,13 \%)$ & 0.003 \\
\hline \multicolumn{4}{|l|}{ Laboratory test results during ICU stay ${ }^{\mathrm{d}}$} \\
\hline Hemoglobin (g/L) & $98.9 \pm 20.0$ & $107.7 \pm 18.8$ & 0.003 \\
\hline Cardiac troponin I (ng/ml) & $0.03(0.01,0.13)$ & $0.01(0.01,0.02)$ & $<0.001$ \\
\hline Brain natriuretic peptide (pg/ml) & $510(186,1194)$ & $164(90,410)$ & $<0.001$ \\
\hline Serum potassium (mmol/L) & $3.9 \pm 0.6$ & $4.2 \pm 0.5$ & $<0.001$ \\
\hline Serum magnesium (mmol/L) & $0.87 \pm 0.16$ & $0.94 \pm 0.16$ & 0.005 \\
\hline
\end{tabular}


Data are presented as number (\%), median (interquartile range) or mean \pm SD.

POAF: postoperative atrial fibrillation; ICU: intensive care unit; APACHE II: Acute Physiology and Chronic Health Evaluation II.

${ }^{a}$ Rated according to routine preoperative tests for elective surgery: summary of updated National Institute for Health and Care Excellence (NICE) guidance [24].

${ }^{\mathrm{b}}$ Rated according to American College of Cardiology/American Heart Association guideline update for perioperative cardiovascular evaluation for noncardiac surgery [25].

c The worst score within 24 hours after ICU admission.

$\mathrm{d}$ The last one before POAF in the POAF group. The worst one after ICU admission in the control group.

\section{Table 3. Pathological diagnoses}




\begin{tabular}{|c|c|c|c|}
\hline & $\begin{array}{c}\text { POAF group } \\
(\mathrm{n}=68)\end{array}$ & $\begin{array}{c}\text { Control group } \\
(\mathrm{n}=134) \\
\end{array}$ & $\mathrm{P}$ value \\
\hline Pathologically diagnosed cancer & $48(70.6 \%)$ & $110(82.1 \%)$ & 0.061 \\
\hline TNM stage of cancer $^{a}$ & $(\mathrm{n}=48)$ & $(\mathrm{n}=110)$ & \\
\hline T stage & & & 0.126 \\
\hline T0 & $0(0.0 \%)$ & $0(0.0 \%)$ & \\
\hline $\mathrm{T} 1$ & $5(10.4 \%)$ & $27(24.5 \%)$ & \\
\hline $\mathrm{T} 2$ & $12(25.0 \%)$ & $31(28.2 \%)$ & \\
\hline T3 & $22(45.8 \%)$ & $40(36.4 \%)$ & \\
\hline $\mathrm{T} 4$ & $9(18.8 \%)$ & $12(10.9 \%)$ & \\
\hline $\mathrm{N}$ stage & & & 0.176 \\
\hline No & $26(54.2 \%)$ & $77(70.0 \%)$ & \\
\hline N1 & $13(27.1 \%)$ & $23(20.9 \%)$ & \\
\hline N2 & $5(10.4 \%)$ & $7(6.4 \%)$ & \\
\hline N3 & $4(8.3 \%)$ & $3(2.7 \%)$ & \\
\hline M stage & & & 0.514 \\
\hline M0 & $41(85.4 \%)$ & $98(89.1 \%)$ & \\
\hline M1 & $7(14.6 \%)$ & $12(10.9 \%)$ & \\
\hline Cancer stage $^{\mathrm{a}}$ & $(\mathrm{n}=48)$ & $(\mathrm{n}=110)$ & 0.135 \\
\hline Stage 1 & $5(10.4 \%)$ & $26(23.6 \%)$ & \\
\hline Stage 2 & 21 (43.8\%) & 51 (46.4\%) & \\
\hline Stage 3 & 15 (31.3\%) & 21 (19.1\%) & \\
\hline Stage 4 & 7 (14.6\%) & 12 (10.9\%) & \\
\hline
\end{tabular}

Data are presented as number (\%).

POAF: postoperative atrial fibrillation; TNM: tumor, node and metastasis.

a Rated according to the American Joint Committee on Cancer (AJCC) Cancer Staging Manual-7th Edition [26].

Table 4. 3-year outcomes 


\begin{tabular}{|c|c|c|c|c|}
\hline & $\begin{array}{c}\text { POAF group } \\
(\mathrm{n}=68)\end{array}$ & $\begin{array}{c}\text { Control group } \\
(n=134)\end{array}$ & $\begin{array}{l}\text { Estimated effects } \\
(95 \% \mathrm{CI})\end{array}$ & $\begin{array}{c}P \\
\text { value }\end{array}$ \\
\hline \multicolumn{5}{|l|}{ Primary endpoint } \\
\hline MACEs within 3 years after surgery & $44(64.7 \%)$ & $31(23.1 \%)$ & $\begin{aligned} \mathrm{OR}= & 6.091 \\
& 11.543)\end{aligned}$ & $<0.001$ \\
\hline Cardiovascular death $^{\mathrm{a}}$ & $8(11.8 \%)$ & $10(7.5 \%)$ & $\begin{array}{c}\mathrm{OR}=1.653(0.621- \\
4.403)\end{array}$ & 0.311 \\
\hline Nonfatal cardiac arrest ${ }^{b}$ & $4(5.8 \%)$ & $3(2.2 \%)$ & $\begin{aligned} & \mathrm{OR}= 2.729(0.593- \\
&12.560)\end{aligned}$ & 0.228 \\
\hline Acute myocardial infarction ${ }^{\mathrm{c}}$ & $17(25.0 \%)$ & $20(14.9 \%)$ & $\begin{array}{c}\mathrm{OR}=1.900(0.919- \\
3.927)\end{array}$ & 0.080 \\
\hline Congestive heart failure ${ }^{d}$ & $32(47.1 \%)$ & $10(7.5 \%)$ & $\begin{array}{c}\mathrm{OR}=11.022(4.947- \\
24.559)\end{array}$ & $<0.001$ \\
\hline Ischemic stroke ${ }^{\mathrm{e}}$ & $6(8.8 \%)$ & $3(2.2 \%)$ & $\begin{array}{c}\mathrm{OR}=4.226 \\
(1.023,17.456)\end{array}$ & 0.032 \\
\hline \multicolumn{5}{|l|}{ Secondary endpoints } \\
\hline MACEs in hospital after surgery & $38(55.9 \%)$ & $10(7.55 \%)$ & $\begin{array}{c}\mathrm{OR}=15.707(7.039- \\
35.049)\end{array}$ & $\begin{array}{c}< \\
0.001\end{array}$ \\
\hline Cardiovascular death $^{a}$ & $1(1.5 \%)$ & $0(0.0 \%)$ & --- & --- \\
\hline Nonfatal cardiac arrest & $2(2.9 \%)$ & $2(1.5 \%)$ & $\mathrm{OR}=2.000(0.276-$ & 0.604 \\
\hline Acute myocardial infarction ${ }^{\mathrm{c}}$ & $12(16.9 \%)$ & $5(3.7 \%)$ & $\begin{aligned} \mathrm{OR}= & 5.529(1.860- \\
& 16.434)\end{aligned}$ & 0.001 \\
\hline Congestive heart failure ${ }^{d}$ & $30(44.1 \%)$ & $8(6.0 \%)$ & $\begin{array}{c}\mathrm{OR}=12.434(5.261- \\
39.388)\end{array}$ & $\begin{array}{c}< \\
0.001\end{array}$ \\
\hline Ischemic stroke $^{\mathrm{e}}$ & $1(1.5 \%)$ & $0(0.0 \%)$ & -- & -- \\
\hline $\begin{array}{l}\text { Other postoperative complications in } \\
\text { hospital }\end{array}$ & $47(69.1 \%)$ & $25(18.7 \%)$ & $\begin{array}{c}\mathrm{OR}=9.758(4.976- \\
19.136)\end{array}$ & $\begin{array}{c}< \\
0.001\end{array}$ \\
\hline Respiratory failure ${ }^{f}$ & $11(16.2 \%)$ & $1(0.7 \%)$ & $\begin{array}{c}\mathrm{OR}=25.667(3.237- \\
203.505)\end{array}$ & $\begin{array}{c}< \\
0.001\end{array}$ \\
\hline Severe sepsis or septic shock $g$ & $25(36.8 \%)$ & $10(7.5 \%)$ & $\begin{aligned} \mathrm{OR}= & 7.209(3.203- \\
& 16.226)\end{aligned}$ & $\begin{array}{c}< \\
0.001\end{array}$ \\
\hline Circulatory insufficiency $\mathrm{h}$ & $14(20.6 \%)$ & $12(9.0 \%)$ & $\begin{array}{c}\mathrm{OR}=2.636(1.144- \\
6.075)\end{array}$ & 0.020 \\
\hline $\begin{array}{l}\text { New-onset arrhythmia (non-atrial } \\
\text { fibrillation) }{ }^{i}\end{array}$ & $27(39.7 \%)$ & $7(5.2 \%)$ & $\begin{array}{c}\mathrm{OR}=11.948(4.844- \\
29.468)\end{array}$ & $<<$ \\
\hline Acute kidney injury ${ }^{j}$ & $19(27.9 \%)$ & $3(2.2 \%)$ & $\begin{array}{c}\mathrm{OR}=16.932(4.798- \\
59.758)\end{array}$ & $\begin{array}{c}< \\
0.001\end{array}$ \\
\hline Mechanical ventilation time ${ }^{\mathrm{k}}$ (hour) & $\begin{array}{c}36.0(5.5,168.5) \\
\quad(n=45)\end{array}$ & $\begin{array}{c}7.0(4.0,13.5) \\
\quad(n=85)\end{array}$ & $\begin{array}{c}\text { Median } \mathrm{D}=29.0(19.4 \\
41.7)\end{array}$ & $\begin{array}{c}< \\
0.001\end{array}$ \\
\hline LOS in ICU after surgery (day) & $5.0(3.0,11.0)$ & $1.0(1.0,2.3)$ & $\begin{array}{c}\text { Median } \mathrm{D}=4.0(1.1 \\
10.4)\end{array}$ & $\begin{array}{c}< \\
0.001\end{array}$ \\
\hline LOS in hospital after surgery (day) & $17.5(13.0,31.0)$ & $11.5(8.0,18.3)$ & $\begin{array}{c}\text { Median } \mathrm{D}=6.0(2.2 \\
13.1)\end{array}$ & $<<$ \\
\hline All-cause mortality in hospital & $6(8.5 \%)$ & $1(0.7 \%)$ & $\begin{array}{c}\mathrm{OR}=13.015(1.535 \\
110.325)\end{array}$ & 0.006 \\
\hline $\begin{array}{l}\text { 3-year overall survival after surgery } \\
\text { (month) }\end{array}$ & $25.8(22.6,28.9)$ & $31.4(30.1,32.8)$ & $\begin{array}{c}\mathrm{HR}=1.598(1.007- \\
2.538)\end{array}$ & 0.043 \\
\hline
\end{tabular}

Data are expressed as n (\%) or median/mean (95\% CI). 
POAF: postoperative atrial fibrillation; CI: confidence interval; MACEs: major adverse cardiovascular events; OR: odds ratio; D; difference; LOS: length of stay; ICU: intensive care unit; HR: hazard ratio; ICD-10: the International Classification of Diseases-10th revision.

${ }^{a}$ Any death caused by specific cardiovascular diseases (myocardial infarction [I21.X in the ICD-10 code], heart failure [I50.X], arrhythmia [I49.900], and cardiogenic shock [R57.001]), which might be combined with other diseases.

${ }^{\mathrm{b}}$ Cardiac arrest (ventricular fibrillation, pulseless ventricular tachycardia, asystole, and pulseless electrical activity) caused by various reasons, followed by return of spontaneous circulation after cardiopulmonary resuscitation, and patient survived (I46.9).

c Diagnosed when the CTnI concentration was higher than the diagnostic criteria for myocardial infarction, together with the emergence of new Q wave ( $\geq 0.03 \mathrm{~s}$ ) or the persistent change of ST-T segment ( $\geq 4$ days) (I21.X) .

$\mathrm{d}$ The acute attack or aggravation of the symptoms or signs of heart failure, accompanied by serum brain natriuretic peptide elevation (>400 pg/ml), and required medical treatment (I50.X).

e A new-onset, persistent (>24 hours) focal neurologic deficit with computed tomography or magnetic resonance imaging evidence of cerebral infarction (I63.9).

${ }^{\mathrm{f}}$ Diagnosed when $\mathrm{PaO}_{2}<60 \mathrm{mmHg}$ (room air), oxygenation index $<300$, and/or arterial oxygen saturation $<90 \%$, and required oxygen therapy or mechanical ventilation for more than 48 hours.

g Systematic inflammatory response syndrome caused by a known or suspected infection, accompanied by at least one new organ dysfunction or required vasopressor therapy to maintain blood pressure.

${ }^{\mathrm{h}}$ Requirement of vasopressors and/or inotropic therapy for more than 24 hours.

${ }^{\mathrm{i}}$ New-onset arrhythmia other than atrial fibrillation. Diagnosis was confirmed by a 12-lead electrocardiogram. Medical treatment and/or electrical conversion were required. 
${ }^{j}$ Serum creatinine increased to more than $26.5 \mathrm{nmol} / \mathrm{L}$ within 48 hours after surgery, or serum creatinine increased to more than 1.5 times baseline within 7 days, or urine output $<0.5 \mathrm{ml} / \mathrm{kg} / \mathrm{hr}$ for more than 6 hours.

${ }^{\mathrm{k}}$ Results of those who were admitted to the ICU with endotracheal intubation. 
Table 5. Factors in association with 3-year MACEs a

\begin{tabular}{|c|c|c|c|c|}
\hline & \multicolumn{2}{|c|}{ Univariate analysis } & \multicolumn{2}{|c|}{ Multivariate analysis ${ }^{b}$} \\
\hline & OR $(95 \% C I)$ & $\begin{array}{c}p \\
\text { value }\end{array}$ & OR $(95 \% C I)$ & $p$ value \\
\hline New-onset POAF & $6.091(3.215-11.543)$ & $<0.001$ & $5.448(2.202-13.481)$ & $<0.001$ \\
\hline Preoperative coronary heart disease & $1.942(1.019-3.703)$ & 0.044 & $2.974(1.126-7.858)$ & 0.028 \\
\hline Preoperative non-AF arrhythmia ${ }^{\mathrm{c}}$ & 4.935 (1.267-19.225) & 0.021 & --- & --- \\
\hline Left atrial enlargement & $2.307(1.102-4.831)$ & 0.027 & --- & --- \\
\hline Emergency operation & $3.733(1.814-7.683)$ & $<0.001$ & --- & --- \\
\hline APACHE II score at ICU admission & 1.065 (1.008-1.125) & 0.025 & --- & -- \\
\hline Hemoglobin <110 g/L & $2.606(1.368-4.965)$ & 0.004 & --- & --- \\
\hline Cardiac troponin I >0.04 ng/ml & $\begin{array}{l}12.675(5.759- \\
27.894)\end{array}$ & $<0.001$ & $\begin{array}{l}19.137(5.642- \\
64.909)\end{array}$ & $<0.001$ \\
\hline Brain natriuretic peptide $>100 \mathrm{pg} / \mathrm{ml}$ & $5.483(2.199-13.667)$ & $<0.001$ & --- & -- \\
\hline $\begin{array}{l}\text { Other complications in hospital (within } 30 \\
\text { days) d }\end{array}$ & 4.115 (2.230-7.585) & $<0.001$ & --- & --- \\
\hline
\end{tabular}

MACEs: major adverse cardiovascular events; OR: odds ratio; CI: confidence interval; POAF: postoperative atrial fibrillation; AF: atrial fibrillation; APACHE II: Acute Physiology and Chronic Health Evaluation II; ICU: intensive care unit.

a Include cardiovascular death, nonfatal cardiac arrest, acute myocardial infarction, congestive heart failure, and ischemic stroke.

${ }^{\mathrm{b}}$ Factors with $p<0.10$ in univariate analyses are included in the multivariate Logistic regression model. Multivariate Logistic regression analysis was performed by using a Backward (Wald) stepwise procedure. Hosmer-Lemeshow test: $\chi^{2}=4.207, \mathrm{df}=6, p=0.649$.

${ }^{\mathrm{c}}$ Includes sinus tachycardia (2 cases), sinus bradycardia (2 cases), atrial premature beat (2 cases), ventricular premature beat (1 case), supraventricular tachycardia (1 case), atrioventricular block (2 cases), and bundle branch block (1 case).

d Include respiratory failure, severe sepsis or septic shock, circulatory insufficiency, new-onset non-AF arrhythmia, and acute kidney injury. 


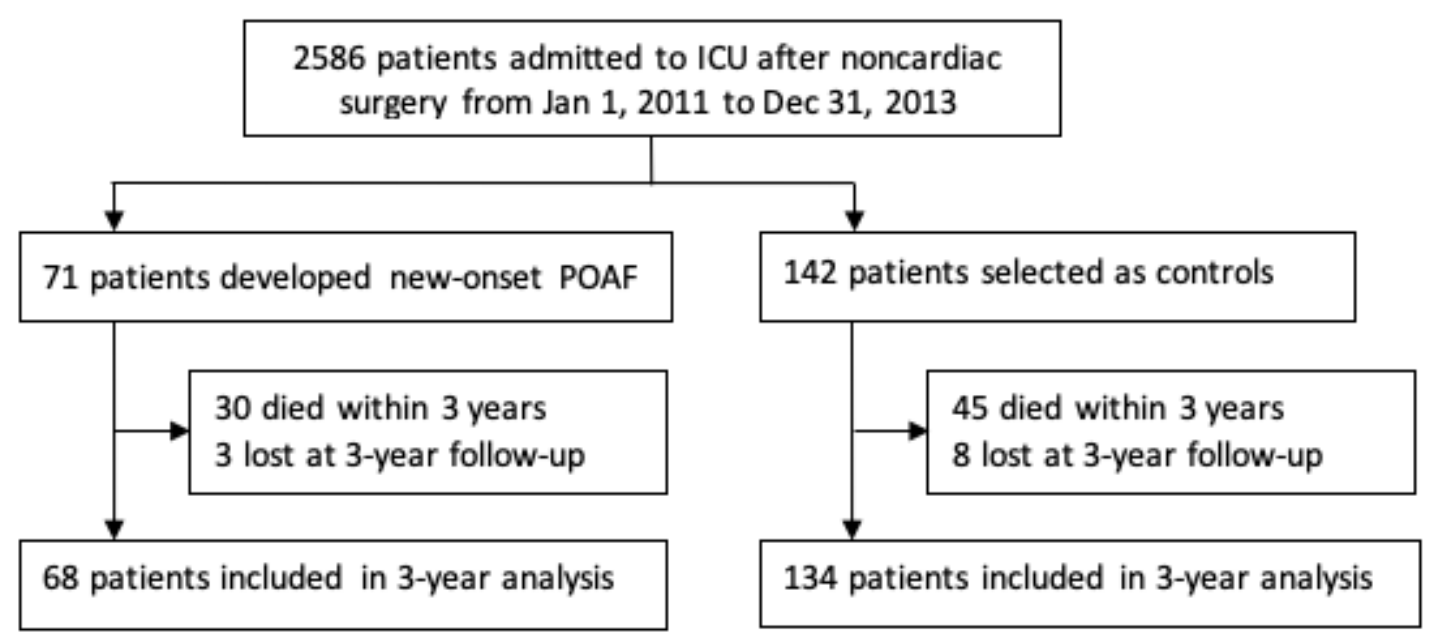

Figure 1

Flowchart of the study.

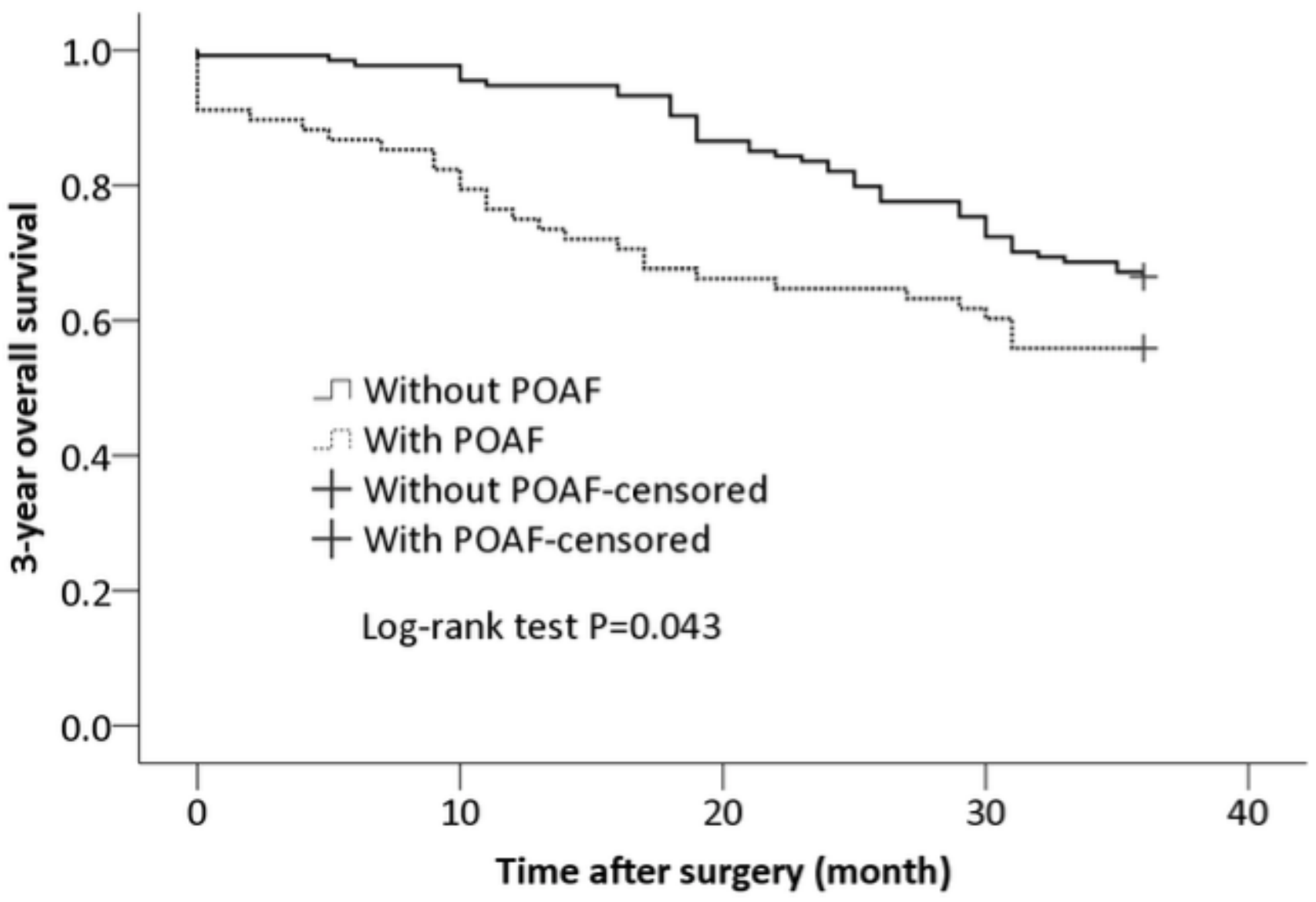

Figure 2

The 3-year overall survival in patients with or without now-onset POAF. 


\section{Supplementary Files}

This is a list of supplementary files associated with this preprint. Click to download.

- SubmitSupplement1.Factorsunivariateanalyses.docx

- SubmitSTROBEChecklist.docx 